\title{
Subdural placement of an epidural catheter detected by nerve stimulation
}

\author{
[Positionnement sous-dural d'un cathéter épidural détecté par stimulation
}

nerveuse et confirmé par tomographie]

Pierre Lena MD, ${ }^{\star}$ René Martin MD FRCP $\dagger$

Purpose: Subdural placement of an epidural catheter is rare and difficult to detect. Electrical stimulation of the epidural space can be useful to detect such an event. The purpose of the present case report is to confirm the efficacy of electrical stimulation to detect a subdural placement of an epidural catheter and to illustrate this unusual positioning by computed tomography (CT) scan images.

Clinical features: A 51 -yr-old man was scheduled for an aortoiliac bypass on a combined epidural and general anesthesia technique. Electrical epidural stimulation was used. A very low threshold of $0.3 \mathrm{~mA}$ was observed with diffuse response movement at T3 and at TI0, without cerebrospinal fluid return on catheter aspiration. An injection of $12 \mathrm{~mL}$ of $2 \%$ lidocaine with epinephrine I/200,000 produced signs of iv injection of local anesthetic and an extensive block. Subdural placement of the catheter, suspected by the low current threshold response to epidural catheter stimulation, was confirmed by CT scan imaging.

Conclusion: The present case report confirms that electrical stimulation of the epidural space is useful to detect misplacement of epidural catheter such as a subdural placement. CT scan imaging of subdural positioning of an epidural catheter is presented.

Objectif : Le cathétérisme de l'espace sous-dural est rare et de diagnostic difficile. La stimulation électrique de l'espace épidural peut être utile pour détecter un tel évènement. Le présent cas clinique a pour but de confirmer l'utilité de cette technique pour détecter le positionnement sous-dural d'un cathéter épidural et d'illustrer par tomographie ce phénomène.

Éléments cliniques: Un homme de 51 ans devait subir un pontage aorto-iliaque sous anesthésie combinée épidurale-générale. La stimulation épidurale du cathéter a été utilisée. Un courrant électrique très faible de 0,3 mA a produit une réponse motrice diffuse au niveau de T3 et de T10, sans évidence de retour de liquide céphalo-rachidien. Une injection de $12 \mathrm{~mL}$ de lidocaïne $2 \%$ avec épinéphrine //200 000 a occasionné des symptômes d'injection iv d'anesthésiques locaux ainsi qu'un blocage nerveux extensif. Une position sous-durale du cathéter a été soupçonnée devant la réponse motrice diffuse à la stimulation de faible intensité, phénomène confirmé par tomographie. Conclusion : Le présent cas confirme l'utilité de la stimulation épidurale dans la détection d'un cathétérisme sous-dural par un cathéter épidural et la tomographie faite à cette occasion permet de visualiser cette entité pour la première fois.

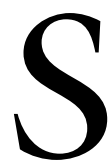

OME risks can accompany the injection of local anesthetic into the epidural space including unintentional subdural, subarachnoid or iv drug injection. ${ }^{1}$ An incidence of $0.82 \%$ of subdural injection is reported. ${ }^{1}$ Clinical manifestations of subdural block will vary according to:

1. The exact location of the tip of the catheter: the local anesthetic injection into the anterior subdural space may be associated with high motor and sensory blocks and even loss of consciousness, while posterior subdural injection usually presents as a failed spinal block or patchy epidural block, of slow onset, requiring large volumes of local anesthetic for correction.

2. The speed of the injection and volume of local anesthetic injected: slow injection of small volume in the posterior compartment will produce little or no motor block and/or hypotension while rapid injection of higher volume might lead to rupture of the fragile subarachnoid membrane with subsequent spreading of the local anesthetic into the intrathecal space. ${ }^{2}$ 
It is suggested that the diagnosis of a subdural catheter placement be confirmed radiologically using contrast media. Thus many epidural catheters may be placed subdurally unbeknownst to the clinicians. Electrical stimulation (1-10 mA) can be used to confirm the location of epidural catheters and to detect a subarachnoid or an intravascular placement of the catheter. ${ }^{3,4}$

This report describes the use of electrical stimulation to detect a subdural epidural catheter placement which was confirmed by computed tomography (CT) scan.

\section{Case report}

A 51-yr-old man, who was a heavy smoker, with generalized vascular disease, was scheduled for an abdominal arterial aortic aneurysm repair with aorto bi-iliac bypass. An anesthetic technique combining epidural and general anesthesia was planned.

The epidural space was easily located by a loss of liquid resistance technique, with the patient in a left lateral supine position. The puncture was carried out at the T10-Tll interspace, using an insulated $19 \mathrm{G}$ Tuohy needle. A nerve stimulator (Dakmed model 750 digital, C.R. Bard, Inc., Tewksbury, MA, USA) set at a frequency of $1 \mathrm{~Hz}$ with a pulse width of 200 msec, with the cathode lead connected to the Tuohy needle and the anode to an electrode over the upper and lower extremities, was used to stimulate the epidural space in search of an electric threshold. ${ }^{5,6}$ The threshold was found at $7 \mathrm{~mA}$ with a segmental bilateral motor response at the Tl0 level, confirming the epidural location of the Tuohy needle.

A $20 \mathrm{G}$ epidural catheter (Pajunk stimulong catheter with central opening and live mandarin) was threaded freely $5 \mathrm{~cm}$ into the epidural space. A venous backward return of blood into the catheter was then observed. At that time, the stimulation threshold through the catheter was $0.8 \mathrm{~mA}$, with the cathode lead of the stimulator connected to the catheter (Pajunk stimulong adapter with electrical connector). A diffuse positive motor response involving the left chest at T3 level and a bilateral response at T10 was observed. The catheter was then withdrawn $1 \mathrm{~cm}$, with disappearance of the backward venous blood flow return. However, the threshold remained at $0.8 \mathrm{~mA}$ with the same diffuse motor response. Twelve mililitres of $2 \%$ lidocaine with $1 / 200,000$ epinephrine were then injected slowly, after a negative aspiration test for blood and cerebrospinal fluid.

Bradycardia, hypertension, faintness, and dizziness associated with a metallic taste, and several convulsive movements were observed, evoking an iv injection.

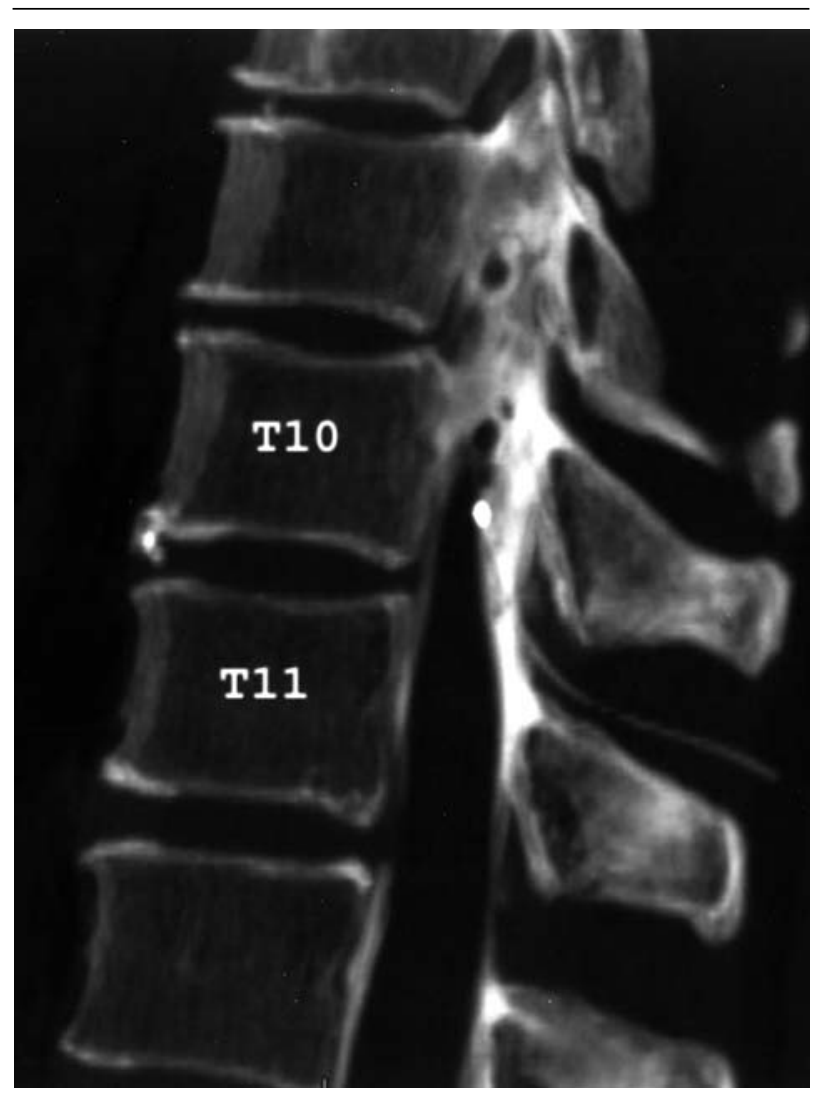

FIGURE 1 Computed tomography (CT) scan of the spine with the subdural catheter (lateral view).

Clinical recovery was rapid. The patient was then turned on his back, in good condition, with normal arterial blood gases and a normal activated clotting time. The epidural catheter was again stimulated and a threshold of $0.3 \mathrm{~mA}$ was observed, with the same type of diffuse motor response as before. The patient was monitored for an eventual block appearance which developed in the following $15 \mathrm{~min}$, with a cutaneous level to pinprick at T10. Subdural placement of the epidural catheter was suspected at that time, and the catheter was not used, but left in situ.

Surgery was carried out as planned under general anesthesia (remifentanil, sevoflurane, oxygen, cisatracurium) and lasted two hours. During the surgical procedure, $80 \mathrm{~min}$ after the blood backward flow return in the catheter, the patient received $0.5 \mathrm{mg} \cdot \mathrm{kg}^{-1}$ of heparin. The patient awoke rapidly after his surgery, without evidence of residual block.

After leaving the recovery room, a radiological and a CT scan assessment were undertaken (Figures 1-3). The examinations were conducted using an injection 


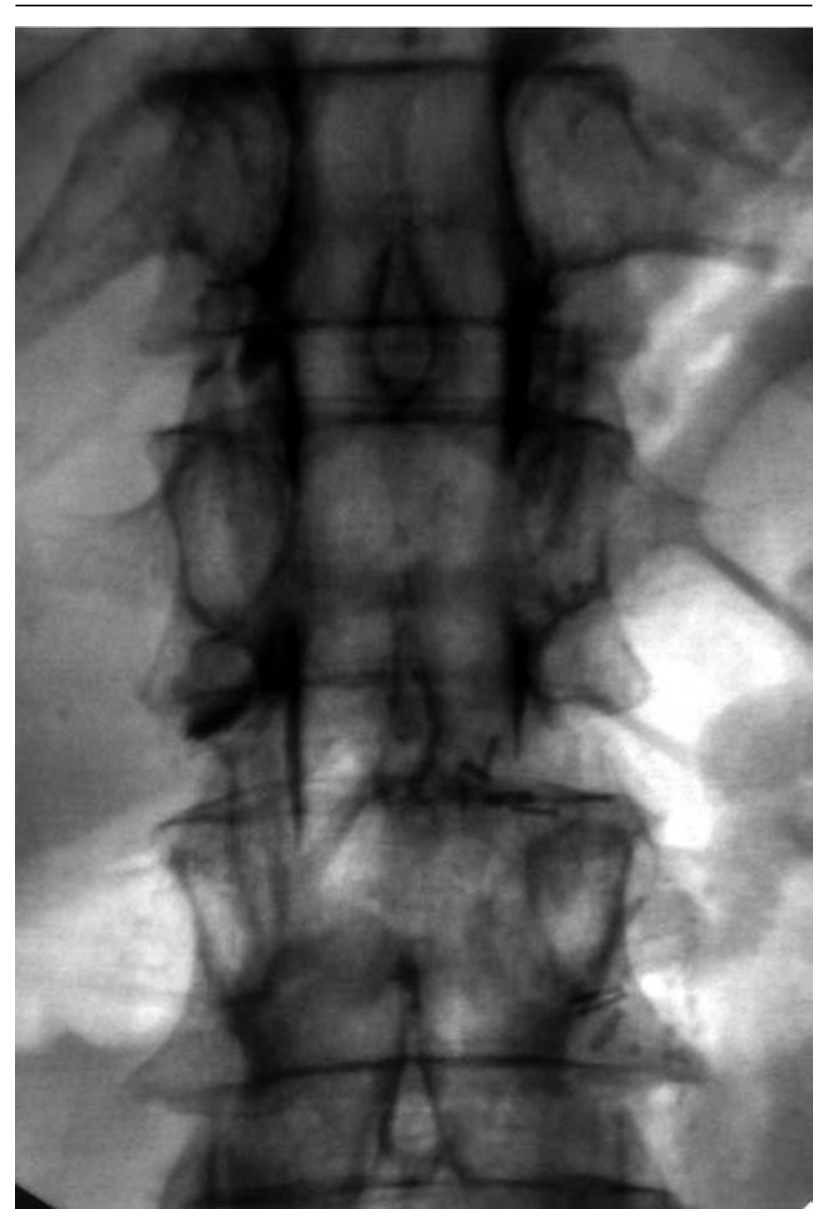

FIGURE 2 Radiography of the spine with the subdural catheter (antero-posterior view).

of $5 \mathrm{~mL}$ of contrast media, and confirmed a subdural location of the catheter, the tip directed towards the right root of Tl0 (Figures 1-3). In fact, the $5 \mathrm{~mL}$ of contrast media spanned seven vertebral spaces without any of the usual characteristics of subarachnoid or epidural diffusion following contrast media injection (Figure 2).

The postoperative period was uneventful, analgesia being provided by a patient-controlled analgesia morphine device for the first $48 \mathrm{hr}$. The catheter was withdrawn $18 \mathrm{hr}$ after the surgery, $12 \mathrm{hr}$ after the administration of $0.40 \mathrm{~mL}$ of enoxaparine. No neurological events were observed in the follow-up period, and the patient was discharged from hospital six days after his surgery.

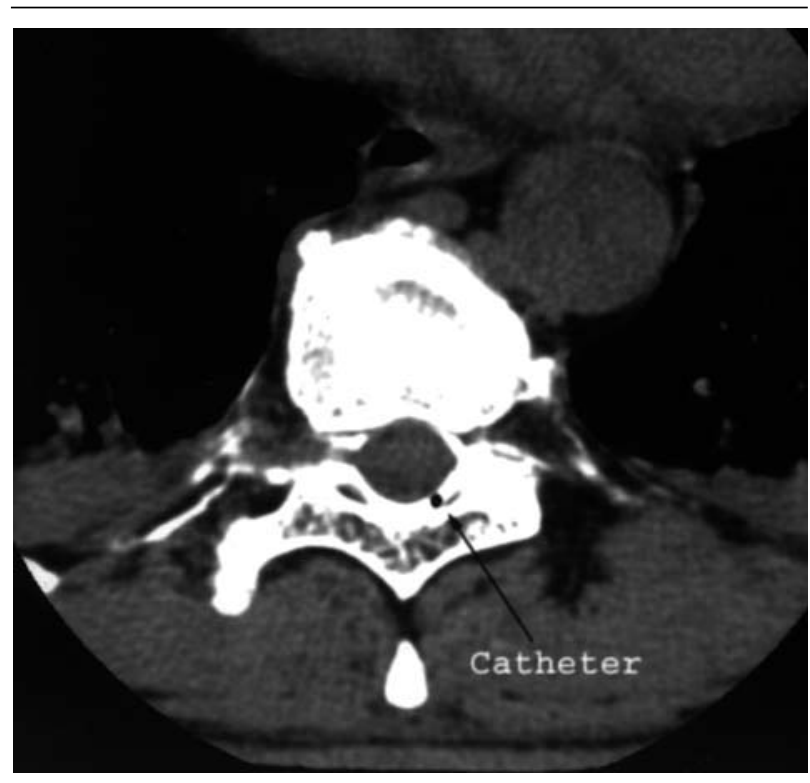

FIGURE 3 Computed tomography (CT) scan of the spine with the subdural catheter (cross section view).

\section{Discussion}

Subdural catheter placement of an epidural catheter was suspected using electrical stimulation, and confirmed by CT scan. One characteristic of subdural catheter placement is that fluid injection into this space can spread a considerable distance, as observed in our case after a $5-\mathrm{mL}$ injection of contrast media. Tsui et al. demonstrated that the threshold current in the intrathecal space required to elicit a motor response is lower that in the epidural space. ${ }^{6}$ They hypothesized that a diffuse motor response involving multiple segments would be exhibited at a low current $(<1 \mathrm{~mA})$ when a catheter was threaded in the subdural space. ${ }^{7}$ The present case report findings are consistent with that hypothesis. A diffuse positive motor response involving the left chest at $\mathrm{T} 3$, and bilateral response at T10 were observed at a low current $(0.8$ and $0.3 \mathrm{~mA}$ ).

The clinical signs of subdural local anesthetic injection are inconsistent, but are sometimes characterized by an extensive spread of sensory anesthesia and occasionally by Horner's syndrome. The only evidence in this case suggesting a subdural catheter placement was provided by the stimulation test with a low current threshold response, and by the fact that although a large part of the $12-\mathrm{mL}$ injection of $2 \%$ lidocaine with epinephrine was possibly iv, a T10 block developed, 
probably with a relatively small volume of local anesthetic diffusing into the subdural space.

The originality of the present case report resides in the CT assessment of the subdural catheter. These are the first published images demonstrating this unusual positioning. A subarachnoid injection of contrast media is characterized by filling of dural sleeves by the media. An epidural diffusion is characterized by a more irregular diffusion of the media, in contrast to the present subdural injection where the diffusion was quite extensive and very homogeneous.

Since the incidence of subdural catheter placement is low, the likelihood of detecting this positioning of a catheter without a stimulation test is probably very small. A low stimulation threshold should alert the anesthesiologist. In fact, the classical test dose used to detect intravascular and subarachnoid catheter misplacement may not detect subdural placement. ${ }^{3,7}$

In light of the present case report, use of a test dose of local anesthetic after a negative aspiration test in conjunction with electrical stimulation of epidural catheter may improve the safety and success rate of epidural anesthesia.

\section{References}

I Mulroy MF, Norris MC, Lin SS. Safety steps for epidural injection of local anesthetics: review of the literature and recommendations. Anesth Analg 1997; 85: 1346-56.

2 Ajar AH, Rathmell JP, Mukberji SK. The subdural compartment. Reg Anesth Pain Med 2002; 27: 72-6.

3 Tsui BC, Gupta S, Emery D, Finucane B. Detection of subdural placement of epidural catheter using nerve stimulation. Can J Anesth 2000; 47: 471-3.

4 Tsui BC, Gupta S, Finucane B. Confirmation of epidural catheter placement using nerve stimulation. Can J Anaesth 1998, 45: 640-4.

5 Tsui BC, Guenther C, Emery D, Finucane B. Determining epidural catheter location using nerve stimulation with radiological confirmation. Reg Anesth Pain Med 2000; 25: 306-9.

6 Tsui BC, Wagner A, Finucane B. The threshold current in the intrathecal space to elicit motor response is lower and does not overlap that in the epidural space: a porcine model. Can J Anesth 2004; 51: 690-5.

7 Crosby ET, Halpern S. Failure of a lidocaine test dose to identify subdural placement of an epidural catheter. Can J Anaesth 1989; 36: 445-7. 